\title{
Evaluation and Improvement of Water Supply Capacity in the Region
}

\author{
Qiao-Xu Qin ${ }^{1} \&$ Yuan-Biao Zhang ${ }^{1,2}$ \\ ${ }^{1}$ Innovation Practice Base of Mathematical Modeling, Electrical and Information College of Jinan University, \\ Zhuhai, China \\ ${ }^{2}$ Key Laboratory of Product Packaging and Logistics of Guangdong Higher Education Institutes, Jinan \\ University, Zhuhai, China \\ Correspondence: Yuan-Biao Zhang, Innovation Practice Base of Mathematical Modeling, Electrical and \\ Information College of Jinan University, Zhuhai, China.
}

Received: October 3, 2018 Accepted: October 29, 2018 Online Published: November 25, 2018

doi:10.5539/jms.v8n4p113 URL: https://doi.org/10.5539/jms.v8n4p113

\begin{abstract}
Aiming at the problem of water shortage in the world, we set up an index to measure the supply capacity of regional water resources, and chose six regions to verify the accuracy of the index. Then we chose the Beijing area to analyze the causes of water shortage combined with the actual situation. After that, we predicted the water supply situation in Beijing area in the next 15 years and explained the impact of future water resources on the residents' life by using the grey prediction method. Then the intervention plan is put forward, and the influence of the intervention plan is added to the evaluation model, and then the water supply capacity of the prognosis is predicted again. The quality of the intervention plan is evaluated, and suggestions for future water resources supply are put forward.
\end{abstract}

Keywords: evaluation index, grey forecasting, driving factors, water resources

\section{Introduction}

\subsection{The Related Background of the Problem}

According to the United Nations, 160 million people (1/4 of the world's population) are short of water. In the last century, water consumption was two times the rate of population growth. Human beings need water resources for industrial, agricultural and residential purposes. There are two main reasons for the shortage of water resources: physical shortage and economic shortage. The physical shortage means that the area of water is not enough to meet the demand. Economic shortage means water in the region, but poor management and lack of infrastructure limits the availability of clean water. Many scientists believe that with climate change and population growth, the problem of water shortage is getting worse. The social-demographic characteristic shows that there are other reasons for shortage (Varis, 2006), which may be the increase of personal consumption, or the increase of industrial consumption or other reasons. Improving and providing clean and clean water has become a key issue.

\subsection{Relevant Scholarship}

Dalson Simon studied the relationship between water investment and economic growth. He believed that initial investment related to water can promote economic growth, and the harm related to water can cause losses to economic growth (Dadson, Hall, Garrick, Sadoff, Grey, \& Whittington, 2017). Olli Varis, who has studied nine case cities, believes that while each city takes different approaches and levels of success in the rational use of water resources, large-scale technological investment and sustainable water management methods are needed. Governments also need to have political will for the environment (Varis, 2006). Thomas Bolognesi links the three characteristics of large cities (maturity, anthropization and centrality) with urban water resource hazards (Bolognesi, 2015). Scholars such as CJVorosmarty believe that the protection of freshwater resources needs to take into account various regional and local threats (Vörösmarty, McIntyre, Gessner, Dudgeon, Prusevich, Green, \& Davies, 2010). MartinaFlorke, who has studied water competition between cities and agriculture driven by climate change and urban growth, thinks there is a good chance of conflict between cities and the agricultural sector in the future (Flörke, Schneider, \& McDonald, 2018). Therefore, it is very helpful for sustainable development and utilization of water resources to discuss the causes of water shortage in a certain region from social, environmental and other aspects. 


\subsection{Research Design}

First, build a model to measure the ability of a region to provide clean water for its population, and to consider the dynamic factors that affect supply and demand. The demand for water resources is divided into agricultural water, industrial water and individual water for residents. Smakhtin established the water stress indicator (WSI) in 2005 (Brown \& Matlock, 2011). According to this idea, we can design a supply matching index Supply Matching Index (SMI) to measure the capacity of water resources provided by the region. Then, on the water shortage map provided by the United Nations, select a country with severe water shortage or moderate water shortage, and determine the water shortage in the area according to the geographic location, natural resources and economic conditions of the area.

The model is then used to predict the water situation in an area in the next 15 years. For short-term prediction, the gray prediction method can be used to predict surface water, groundwater, agricultural water, industrial water and domestic water in the next decade using historical data, and then use the prediction data to calculate supply and demand. Data models are used to predict future water availability in the region. The impact on residents' lives is explained in combination with the predicted results and the actual situation of water supply.

Finally, an intervention plan was proposed for each water shortage in the selected region, and then the evaluation model of impact degree of each intervention plan was roughly predicted by referring to the data, and then the prediction and analysis of future water resources were made again.

\section{The Establishment and Solution of the Model}

\subsection{Model of Regional Water Supply Capacity}

\subsubsection{Model Establishment}

Mission 1 requires the establishment of a model to measure the ability of a region to provide clean water for its population, and to consider the dynamic factors that affect supply and demand. Considering the physical availability of supply, combined with data of People's Republic of China National Bureau of statistics (http://data.stats.gov.cn/easyquery.htm? $\mathrm{cn}=\mathrm{C} 01$ ), the supply sources are divided into surface water and groundwater. In terms of technical availability, since technological advances have a greater impact on the availability of available water, a measure of utilization due to the technical indicator should be added to measure the total supply. This coefficient is different in different areas of value in general, economically developed areas more developed technology, due to technical indicators by using rate coefficient is larger, on the contrary, the backward areas of the coefficient is smaller, so it can be used in GDP to measure the regional economic development status, and then determine the size coefficient of technical indicators.

As the coefficient of utilization rate due to technological progress is related to the economic level of the region, and the economic level in different regions is quite different from the analysis of the problem, the higher the economic level, the higher the technological level of water resources utilization, the larger the coefficient On the contrary, the lower the economic level, the coefficient is smaller. In summary, an "S" -based variable weighting function is constructed to measure the effect of the change of technology level on the utilization rate. The variable weight function is shown below:

$$
f(x)= \begin{cases}\frac{1}{\alpha+\beta e^{-x}}+\gamma & x \geq 0 \\ 0 & x<0\end{cases}
$$

Where $\alpha, \beta, \gamma$, are undetermined constants.

According to the data (Zuo, 2011), the threshold of water utilization rate is [0.2-0.4]. The three regions of Beijing, Jiangsu and Jiangxi are selected. The per capita GDP of these three regions are respectively 4.04, 2 and 0.81 , They correspond to the value of the utilization of $0.4,0.3,0.2$, we can get $f(4.04)=0.4, f(2)=0.3, f(0.81)=0.2$. The solutions have to $\alpha=0.3, \beta=0.05, \gamma=-0.07$. The variable weight function is as shown below:

$$
f(x)= \begin{cases}\frac{1}{2.89+11.81 e^{-x}}+0.08 & x \geq 0 \\ 0 & x<0\end{cases}
$$

Among them, $f(x)$ is the water utilization rate; $x$ is the regional GDP per capita. The function image is shown in Figure 1 below: 


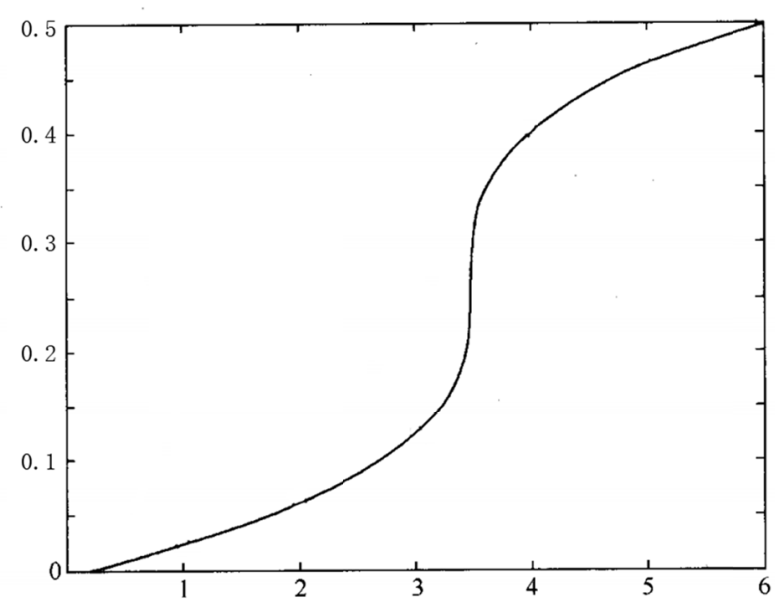

Figure 1. Variable weight function image

Based on the above results, we can get the following formula:

$$
\begin{gathered}
W S=(S W+G W) \times f(x) \\
W D=A W+I W+P W
\end{gathered}
$$

$W S$ is Water supply, $S W$ is Surface water, $G W$ is Ground water, $W D$ is Water demend, $f(x)$ is the water utilization rate, $A W$ is Agricultural water, $I W$ is the Industrial water, and $P W$ is the Personal water.

Smakhtin established the water stress indicator (WSI) in 2005 (Brown \& Matlock, 2011), The indicator is the ratio of water use to average annual net flow, and the larger the WSI, the poorer the state of water resources in the region. In 1989, Falkenmark proposed a water stress index, a measure of water scarcity based on per capita water resources. At present, the United Nations Environment Program uses WSI to measure the degree of water scarcity in a region. Based on the idea of WSI, this paper establishes a "Supply Matching Index (SMI)" to measure the ability of regions to provide water resources. This index is the ratio of water demand to supply, which is the ratio of water supply (WS) to demand (WD), The greater the SMI, the poorer the water supply capacity. The formula for this metric is as follows:

$$
\mathrm{SMI}=\frac{W S(\mathrm{~W} \text { ater supply })}{W D(\mathrm{~W} \text { ater demand })}
$$

After verification, the SMI model has good accuracy

\subsection{Analysis of the Causes of Water Shortage in Beijing}

China has one of the world's worst water shortages, and Beijing has one of the worst. Considering the difficulty of data collection and the familiarity of samples, the Beijing region is selected to explain why and how the region is short of water. Through access to information and data from the two aspects of natural causes in Beijing city and social reasons to explain why Beijing has been the main reason of water shortage in the region, Beijing area, Beijing area of arid climate inherent water pollution is more serious, population expansion in Beijing increased water consumption and other factors, the specific reasons of the water shortage in Beijing area.

\subsubsection{Natural Factors}

The innate climate is drought, and the precipitation is less. Beijing is located in temperate semi-arid and semi humid monsoon climate area. The seasonal and interannual variation of precipitation is large. The summer rainfall accounts for $85 \%$ of the whole year, and the maximum annual precipitation is $1406 \mathrm{~mm}$ (1959). The minimum year is only $242 \mathrm{~mm}$ (1869). The annual precipitation in Beijing has been decreasing in the last half century, and the average precipitation in every 10 years has been reduced from $781.9 \mathrm{~mm}$ in $1950 \mathrm{~s}$ to $574.2 \mathrm{~mm}$ in 90s. Since 1999, Beijing has entered a period of continuous dry water ( $\mathrm{Lu}, \mathrm{Sun}, \& \mathrm{Lu}, 2002)$. The amount of surface water resources attenuated by $59 \%$, the amount of groundwater resources decreased by $37 \%$, and the inbound water decreased by $77 \%$. Statistics from 1956 to 2000 , the average annual rainfall in Beijing is $585 \mathrm{~mm}$, the average annual water resources is 3 billion 740 million $\mathrm{m} 3$, and the average water consumption per capita is $300 \mathrm{~m} 3$, which is $1 / 8$ of the national average level and the $1 / 30$ of the world average level. Such a per capita 
water resource is not only far below the international extreme water shortage standard, but also much lower than the catastrophic standard which endangers the bottom line of human survival. (The extreme shortage of water is $500 \mathrm{~m} 3300 \mathrm{~m} 3$ per capita, which is a disastrous standard that threatens the bottom line of human survival and life) (Zhang, 2013). In addition, the average annual temperature in Beijing in recent years is about 1 degree centigrade higher than that in the early $1980 \mathrm{~s}$, which is about 1.5 degrees centigrade higher than that in 50 and 60s. The decrease of precipitation, the increase of temperature, the increase of evaporation, and the tendency to dry and warm climate are also a key factor for the reduction of surface water resources in Beijing. The Beijing Observatory since 1950, changes in temperature and precipitation are shown in Figute 2 and 3:

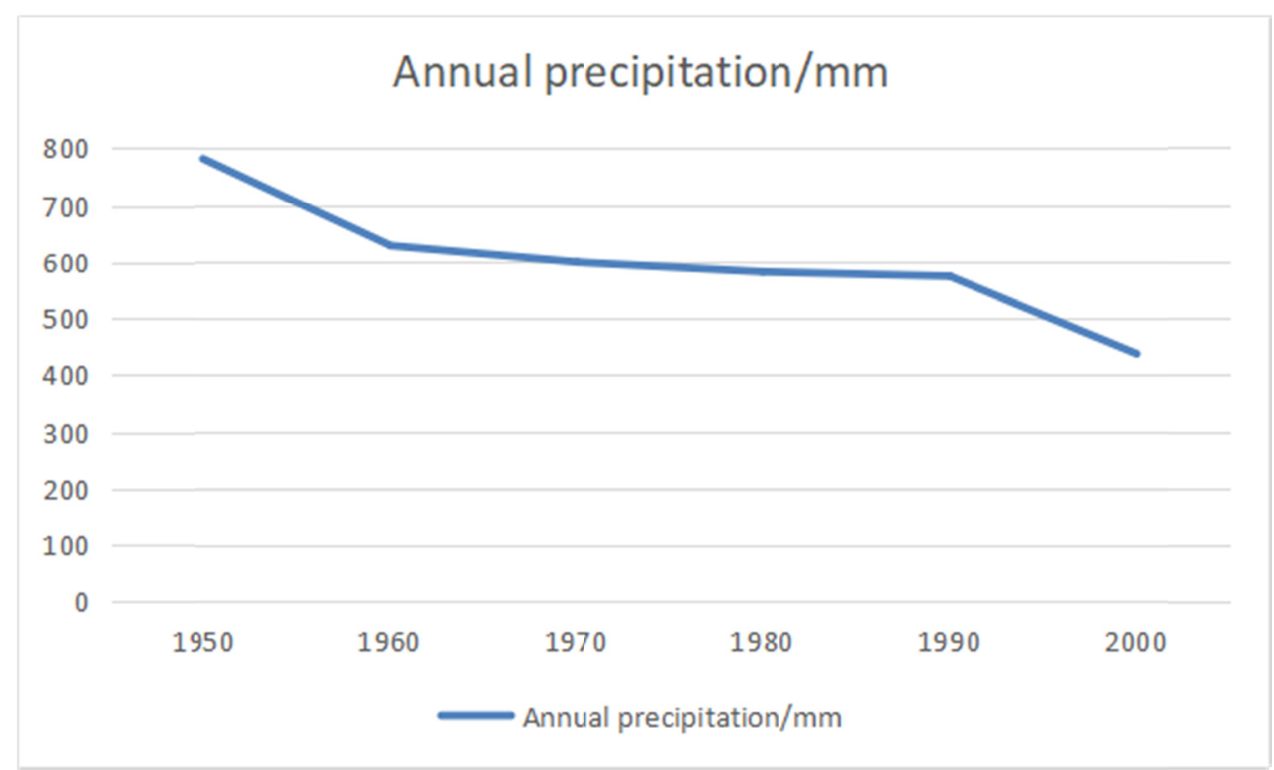

Figure 2. Changes of precipitation in Beijing since 1950s

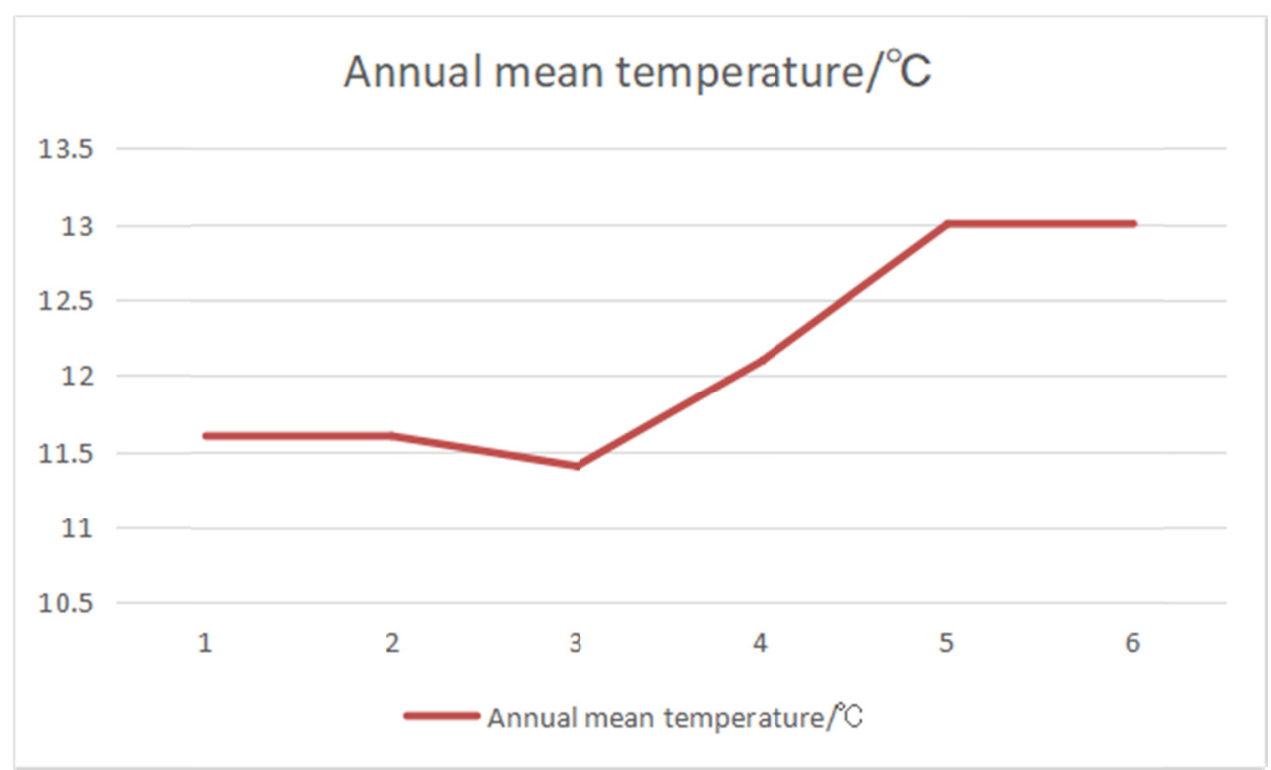

Figure 3. Changes of temperature in Beijing since 1950s

The flow of foreign water is decreasing year by year. The inbound rivers in Beijing include the Chao Bai, Yongding and Daqing rivers, and the inbound water can be used mainly from the upper reaches of the Chao Bai River. In Beijing, 90\% of the surface water can be used from Miyun Reservoir and Guanting reservoir. Data show that two large reservoirs to greatly reduce the amount of water in Guanting reservoir, 1950s annual inflow of 1 billion 930 million m3 was 430 million m3 in 90s; Miyun Reservoir 60 70's annual inflow of 1 billion 200 
million m3, 790 million m3 in 90s; since 1999 two successive years of drought, the reservoir can be used to water down to the lowest point since the establishment of the database, 2002 two the reservoir can be used to water and was only 173 million $\mathrm{m} 3$. The reason for the attenuation of inbound water is related to the reduction of precipitation, but more importantly, a large number of water storage projects have been built upstream and the water use for industrial and agricultural production has been increased. 267 large and large reservoirs were built in the upper reaches of Guanting reservoir, and the irrigation area of 363 thousand and $600 \mathrm{hm} 2$ was developed, and high water consumption industry, such as smelting, electric power and chemical industry, was built. Miyun Reservoir upstream also built more than 30 water storage projects, the development of more than $20000 \mathrm{hm}^{2}$ irrigation area and some industrial, retain and use water surge (Gao, Wang, Han, Wang, \& Wang, 2010).

\subsubsection{Social Factors}

Economic development makes Beijing overtake underground water. Beijing is rich in groundwater, the west suburb is located in the front of Yanshan, and there are many rivers in the vicinity. According to the survey of Beijing Geological Engineering Survey Institute, there are 1347 eyes in Beijing in 1950s. However, due to the development of Beijing in recent years, it has consumed a lot of water resources. The nearby water resources have been overexploited for a long time, and have not been adequately supplied, resulting in the shrinking of groundwater resources and the decline of groundwater level.

Water pollution is a serious reduction in the supply of clean water resources. Beijing city sewage emissions of 964 million $\mathrm{m} 3,12$ sewage treatment plant sewage treatment in 434 million of the total $\mathrm{m} 3$, sewage treatment rate is only $45.04 \%$, there are still a lot of waste water discharged into rivers without treatment and seepage wells, pits, the city's $56 \%$ rivers are the river polluted, river water has more than $34.9 \%$ IV water quality standard of which more than $\mathrm{V}$ class of $24.7 \%$, river city is the super class $\mathrm{V}$ water pollution (Beijing development and reform committee). In the upper reaches of the Guanting reservoir large waste water discharged into the reservoir, which reservoir water quality exceeded the class standard of surface water environment, 1997 has been not as the city drinking water, Miyun Reservoir Eutrophication trend in recent years. The standard of groundwater over class III accounted for $47.5 \%$, mainly for total hardness, turbidity and NH3-N exceeding standard. Water pollution has reduced the available water resources and intensified the water crisis.

Population expansion and urbanization increase water consumption. Beijing's urban population has increased rapidly from 12 million 570 thousand in 1999 to 19 million 610 thousand in 2010, an increase of about 56\%. With the decrease of water resources and rapid expansion of cities, the water resources per capita in Beijing decreased to $100 \mathrm{~m} 3$ in 2010 , less than $1 / 20$ of the national average level, and became the lowest area of water resources per capita in the whole country. Because China's urbanization has entered a stage of rapid development, Beijing's special urban functions and advanced economic level will attract more foreign population. The total population of Beijing will continue to grow in the coming years (Wu \& Lu, 2005).

The utilization rate of water resources is low. Beijing's high water consumption industry and agricultural water account for a large proportion of total water consumption. Although the water consumption of industrial and agricultural production is relatively low in the whole country, the economic and technical indicators of water use still have a large gap from the world's advanced level. At present, Beijing has about $30 \%$ of the effective irrigation area without water-saving irrigation measures; flood irrigation water caused a huge waste of resources. Part of the underground water supply pipe network of old, Paomaodilou serious, water leakage rate as high as $17 \%$, more than 100 million years of water leakage $\mathrm{m}^{3}$ (Gao, Wang, Han, Wang, \& Wang, 2010).

\subsection{Prediction of Future Water Conditions}

\subsubsection{Gray Prediction}

Mission requirements to predict the clean water supply capacity for the next 10 years, to the development of things in the future changes of particular time zone for the estimation and prediction, it is in fact the actual process as "grey process", "random" as "grey variables", mainly used in the grey system theory GM $(1,1)$ model for processing. The concrete steps are as follows: (Han, 2014)

Step 1: the necessary inspection and processing of the known data columns. Set the reference data for $x^{(0)}=\left(x^{(0)}(1), x^{(0)}(2), \cdots x^{(0)}(\mathrm{n})\right)$ and calculate the rank ratio of the series:

$$
\lambda(k)=\frac{x^{(0)}(k-1)}{x^{(0)}(k)}(k=2,3, \cdots, \mathrm{n})
$$

If all levels fall within the $X=\left(\mathrm{e}^{-\frac{2}{n+1}}, \mathrm{e}^{\frac{2}{n+1}}\right)$ that can be covered by $\lambda(k)$, then Series $x^{(0)}$ can be used as 
model GM $(1,1)$ and carry out grey prediction. Otherwise, it is necessary to transform the series $x^{(0)}$ to make it fall into the range of capacitive coverage, that is, go to the appropriate constant $c$ and do translation transformation.

$$
y^{(0)}(k)=x^{(0)}(k)+\mathrm{c}(k=1,2, \cdots, \mathrm{n})
$$

The rank ratio of the sequence of $y^{(0)}=\left(y^{(0)}(1), y^{(0)}(2), \cdots y^{(0)}(\mathrm{n})\right)$ is

$$
\lambda_{y}(k)=\frac{y^{(0)}(k-1)}{y^{(0)}(k)} \in X \quad(k=2,3, \cdots, \mathrm{n})
$$

Step 2: to generate a number of columns according to the method generated by the grey prediction accumulation (AGO), we can obtain the predicted value

$$
\begin{aligned}
& \hat{x}^{(1)}(k+1)=\left(x^{(0)}(1)-\frac{b}{a}\right) \mathrm{e}^{-a k}+\frac{b}{a} \quad(k=1,2, \cdots, \mathrm{n}-1) \\
& \hat{x}^{(0)}(k+1)=\hat{x}^{(1)}(k+1)-\hat{x}^{(1)}(k) \quad(k=1,2, \cdots, \mathrm{n}-1)
\end{aligned}
$$

Step 3: the residual $\mathcal{E}(k)$ is calculated:

$$
\varepsilon(k)=\frac{x^{(0)}(k)-\hat{x}^{(0)}(k)}{x^{(0)}(k)}(k=1,2, \cdots, \mathrm{n})
$$

According to the calculation and grey prediction methods, if the residual is less than 0.2 , it can be considered to meet the general requirements, and if the residual is less than 0.1 , it is considered to be higher. Then the level ratio deviation test is carried out. First, the reference data $x^{(0)}(k-1), x^{(0)}(k)$, the calculated level ratio $\lambda_{0}(k)$, and then the development coefficient $\lambda_{0}(k)$ to find the corresponding level deviation.

$$
\rho(k)=1-\left(\frac{1-0.5 a}{1+0.5 a}\right) \lambda_{0}(k)
$$

If the ratio deviation is less than 0.2 , it is considered to meet the general requirement. If the ratio deviation is $<0.1$, it is considered to be higher.

Step 4: according to the needs of the predicted value and the actual problems in the designated area obtained by the model, the corresponding prediction is given.

\subsubsection{Prediction of Water Supply Capacity}

Based on the data of People's Republic of China National Bureau of statistics, the data of surface water, groundwater, agricultural water, domestic water and industrial water in ten years from 2004 to 2014 in Beijing area were obtained. The data of these groups are grey forecast, and the results are shown in table 1 as follows: 
Table 1. Partial prediction results

\begin{tabular}{llllll}
\hline Year & Total surface water & Total amount of groundwater & Agricultural demand & Industrial demand & Domestic water \\
\hline 2015 & 10.727 & 17.351 & 13.263 & 6.615 & 13.886 \\
2016 & 11.033 & 16.978 & 13.794 & 6.879 & 13.627 \\
2017 & 11.347 & 16.614 & 14.346 & 7.153 & 13.373 \\
2018 & 11.669 & 16.257 & 14.920 & 7.439 & 13.124 \\
2019 & 12.001 & 15.907 & 15.517 & 7.736 & 12.879 \\
2020 & 12.343 & 15.566 & 16.138 & 8.045 & 12.639 \\
2021 & 12.694 & 15.231 & 16.784 & 8.366 & 12.403 \\
2022 & 13.055 & 14.904 & 17.455 & 8.700 & 12.172 \\
2023 & 13.427 & 14.584 & 18.154 & 9.048 & 11.945 \\
2024 & 13.809 & 14.270 & 18.880 & 9.409 & 11.723 \\
2025 & 14.202 & 13.964 & 19.635 & 9.785 & 11.504 \\
2026 & 14.606 & 13.664 & 20.421 & 10.175 & 11.290 \\
2027 & 15.021 & 13.370 & 21.238 & 10.582 & 11.080 \\
2028 & 15.449 & 13.083 & 22.088 & 11.004 & 10.873 \\
2029 & 15.888 & 12.802 & 22.972 & 11.444 & 10.670 \\
\hline
\end{tabular}

The actual values of each variable from 2004 to ten in 2014 and the future change values predicted according to the actual values are shown in the following figure:

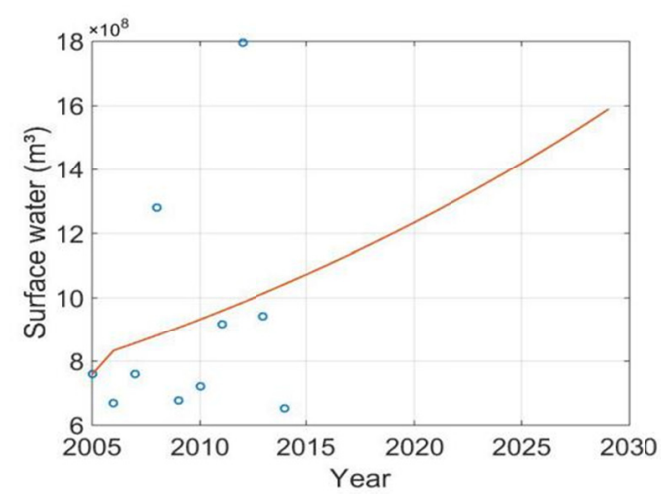

Figure 4. Forecast flow of surface water

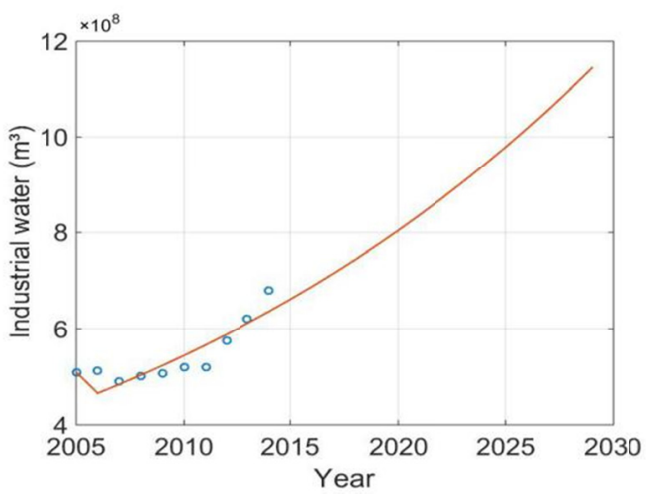

Figure 6. Industrial water consumption

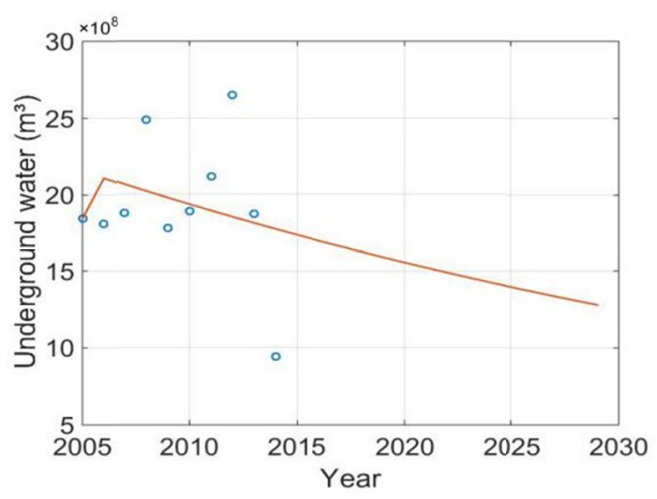

Figure 5. Forecast flow of groundwater

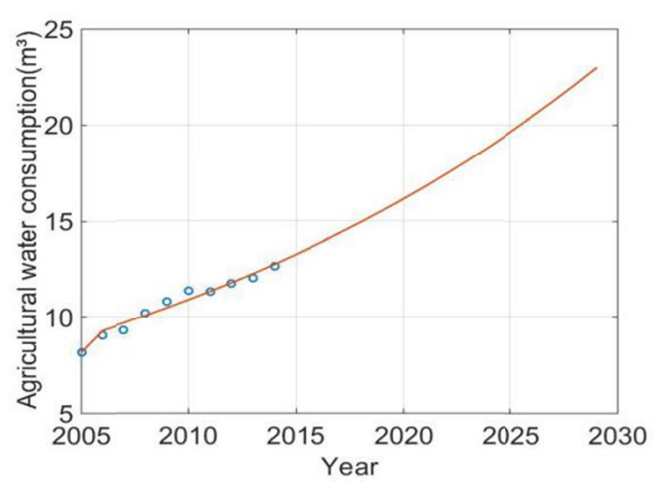

Figure 7. Agricultural water consumption 


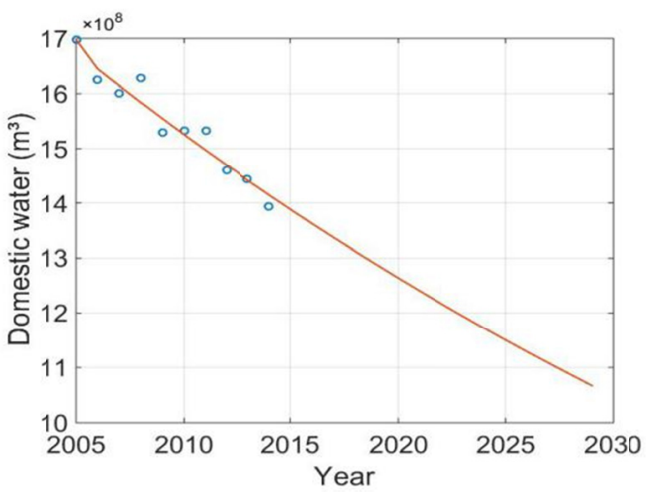

Figure 8. Individual water consumption

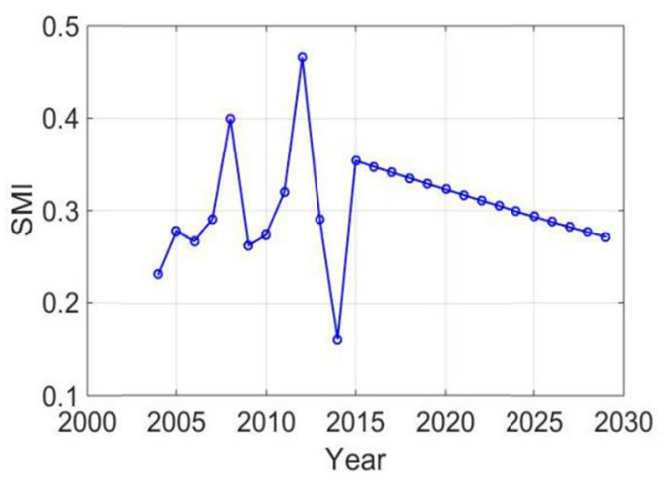

Figure 9. SMI predictive value

It can be seen from the predicted data that surface water will increase year by year in the next 15 years, but from the ordinate point of view, the increase of surface water is not very large, so it will not have a great impact on the total supply of water resources. There will be a downward trend in the groundwater. With the rapid development of Beijing in the next 15 years, industrial water and agricultural water will rise substantially, the future of Beijing's population will continue to increase, while the natural water resources and without a corresponding increase, so the personal consumption will decline significantly, which is mainly reflected in the diagram of curves in 2-7 decreased significantly. The SMI value calculated according to the variation trend of various variables in the next 15 years is shown in Figure 9. SMI will decline year by year in the next few years. That is to say, in the next 15 years, the speed of water resources deterioration will be greater than the speed of water resources management, and water resources will still be in a state of deterioration.

\subsubsection{The Effect of Water Shortage in Reality}

In the future, the lack of water in Beijing will have a certain impact on the living and social life of the residents in Beijing. The following explanation of the specific impact is explained:

The situation of uneven distribution of water resources in Beijing was made. In order to cope with water shortage, Beijing's water supply policy has been forced to adjust many times. Due to the lack of water, Beijing has only adopted the policy of restricting agriculture and industrial water to ensure residents' water consumption for many years, which also leads to the difficulty of taking account of environmental and ecological water consumption, resulting in uneven distribution of water resources.

Water shortage has an impact on agricultural production and production. Due to the limited use of water in agriculture and industry in Beijing, agriculture has to take groundwater as the main source of water, resulting in the destruction of underground soil and the impact on agricultural production.

Water shortage also has an impact on the life of the residents. Due to the lack of water in the reservoir near Beijing, sometimes the power plant will be stopped and the power supply can not be normal. Water loss may even occur at the peak of water consumption. The development of the urban fringe group has to be maintained by mining as the life-saving water for urban combat readiness - deep groundwater (Zhang, 2004).

Water shortage is unfavourable to urban construction. In the case of serious overexploitation of groundwater in urban areas, no more exploitation is allowed. The development of urban construction will rely mainly on the surface water source.

The lack of water is harmful to the ecological environment. Due to the excessive development and pollution of water resources, many rivers in Beijing have rivers without water and polluted by water. Almost no natural self purification capacity of rivers has been caused, resulting in serious environmental pressure. Not only the city downstream water quality seriously exceed the standard, even around the the Imperial Palace now was V class water. In the summer of 2001, due to the lack of city lake water flow, the water bloom phenomenon of Beihai, Shichahai, north moat, floating on the surface with a layer of greasy "green film" for a long time, due to the lack of water, water ecological environment has been regarded as a luxury demand which has not been included in the water demand forecast of Beijing city in the city of Beijing is the development of social economy at the expense of the environment (Zhang, 2004). 


\section{Intervention Plan for Water Shortage}

In 3.2, the reasons for water shortage in Beijing area have been explained from two aspects: natural factors and social factors. In this part, aiming at the reasons of water shortage in Beijing area, this paper puts forward the intervention plan for improving water resources supply capacity.

In terms of natural supply, Beijing region has less water supply because of the drought and low precipitation in Beijing region. At the same time, the decrease of foreign water flow in recent years is also an important reason for the reduction of resources in Beijing. In view of this problem, this paper mainly puts forward three directions of intervention: (1) the development of rain and flood resources. The development of rain and flood resources can not only increase the amount of available water resources, but also reduce the pressure of urban flood control and drainage. For example, in the construction of various types of urban rainwater interception project, city to adopt permeable pavement materials and structure, enhance the rainwater infiltration. The plain area by Tian surface, river and seepage wells increase precipitation infiltration, building rubber dam in river water and groundwater recharge. A suitable location to build rainwater collection project in mountainous area, the maximum flood retaining (Gao, Wang, Han, Wang, \& Wang, 2010). (2) rainwater utilization. With the continuous expansion of the scope of Beijing, the amount of rain water collected in the city of Beijing has also developed rapidly. Among them, the roof rainwater resources account for about $65 \%$ of the urban rainwater resources, and it is easy to collect, and the water quality is relatively stable, which is the main object of urban rainwater utilization. The rainwater collected rainwater infiltration utilization scheme: indirect roof rainwater flows through the high bed penetration purification, and then the road rainwater seep through low green, shallow ditch; greater rainfall, rainwater infiltration ditch into the shallow ditch along the continue infiltration; more than the penetration ability of the rainwater and then discharged into the municipal pipe network. Rainwater can permeate the soil and replenish groundwater. It can also be used directly for non drinkable municipal and industrial water after rain is properly treated. It has become a new source of (Huang, 2003). (3) to continue to strengthen the implementation of the south to North Water Transfer Project. This is the fundamental way to solve the shortage of water resources in the arid regions of the north. The three line in the south to North Water Diversion Project in the middle route project has good water quality, large coverage, artesian water etc., can alleviate the crisis of water resources in Beijing, Tianjin, North China, increase water supply 6 billion 400 million $\mathrm{m} 3$ for Beijing and Tianjin and Henan, along the Hebei city life, industrial water supply, increase 3 billion $\mathrm{m} 3$ for agriculture, is a major initiatives fundamentally solve the crisis of water resources in Beijing city.

For the shortage of water resources caused by economic development in Beijing, the effective management of water resources can be realized by means of law and market. The regulation system of water management in Beijing has been basically formed, and it is necessary to strengthen its implementation. We should carry out the overall plan of water resources. There should be a unified coordination between surface water and groundwater, between urban and rural water, between production and living water, between water resources utilization and protection, between water and water. A water price system that is suitable for market economic system is established. We should encourage water saving and repeated water use to raise the efficiency of water resources utilization by appropriately raising the water price, progressive price increase, seasonal difference price and quality difference price. By consulting the data, we can see that the effective management can reduce the demand for water resources by about $30 \%$.

For the Beijing area due to population expansion brought water and increase the per capita consumption of water shortage, city water restriction work can be carried out, such as the implementation of household water metering and charging system, and to strengthen publicity and education, so that the masses recognize the significance of water saving, water saving consciousness. At the same time, the water saving work should be strengthened in various organs and units. The survey report shows that the effective implementation of water saving system in the general family can generally save water $30 \%-40 \%$ (Yuan, 1986).

There are still many problems of low utilization of water resources in Beijing. First of all, we should vigorously promote water-saving technologies, including water-saving technologies in agriculture, industry and life. Urban water consumption is an important aspect of the consumption of water resources, while living and drainage is also an important source of water pollution. The rational use of household water should be vigorously promoted so that the per capita water consumption can be greatly reduced. We should also promote the use of water-saving sanitary ware. At the same time, the water leakage of the pipeline accounts for more than $20 \%$ of the water supply in the water pipe network. We should also pay attention to the leakage prevention measures of the pipe network. Besides, we should establish and develop water-saving management system (including transaction processing system, information system, decision support system), and urban water resources (surface water and groundwater) management system by using modern high-tech means, so as to achieve the modern management 
of water saving. In terms of agricultural water saving, we should vigorously develop water-saving irrigation technology from traditional extensive irrigation agriculture and rainfed rainfed agriculture to water-saving and efficient modern irrigation agriculture and modern dryland farming. Should be based on the improvement of the surface irrigation mainly promote water-saving irrigation technology, sprinkler irrigation and drip irrigation mode, make full use of rainwater harvesting and water-saving irrigation and other modern dry farming technology. Industry continues to adjust the industrial structure and industrial layout, making the high-tech industry the leading economic development of the capital. We should strictly control the high water consumption industry, accelerate the transformation of traditional industry, popularize the water-saving production process, and improve the recycling rate and recycling rate of industrial water. By consulting the data, the successful implementation of water saving measures in all aspects can increase the water supply by about $40 \%$ (Yuan, 1986).

In view of the serious water pollution in Beijing, the method of sewage resources and reclaimed water can be used to improve the water pollution. Sewage recycling is directly used in agricultural irrigation without toxic substances, or after proper treatment, it will be used for urban public water, and urban sewage will be opened as "second water sources". Ordinary domestic sewage can be used for public water use in cities, such as sprinkling roads, green space water, flushing toilets, rushing to the ground and cooling water and irrigation water for some industries. Construct the water supply pipeline according to water quality (such as the use of double water supply system to provide low standard water for urban residents for outdoor irrigation and toilet flushing, etc.). But the reuse of reclaimed water after two water sewage treatment is an important measure to excavate the potential of water resources locally. The data show that the daily sewage discharge in Beijing is 2 million 640 thousand M3, and less than half of the concentrated treatment is concentrated. The construction of sewage treatment facilities should be strengthened, the sewage treatment rate and the level of purification should be improved so that the sewage treatment can be reached to the available standard. As a non drinking water source, it will be used for industry, agriculture, urban greening and the construction of river and lake environment. If the pollution is improved effectively, the supply can be increased by about $40 \%$.

\section{Prediction of Future Water Resources}

Through the above solutions for each case presented, predict how each kind of solution affect the natural water resources supply and demand and the degree of influence through access to information, again to predict changes of water supply in the next 15 years on the basis of intervention plan, evaluation of each intervention effect.

The first is the development of a new supply of rainwater resources to increase water resources, water resources and roof accounted for about $65 \%$ of total water resources, water diversion project can alleviate the crisis of water resources in Beijing, Tianjin, North China, increase water supply 6 billion 400 million m3 for Beijing and Tianjin and Henan, along the Hebei city life and industry, increase 3 billion $\mathrm{m} 3$ water supply for agriculture, is an important measure to solve the crisis of water resources in Beijing city. Through access to information, this project can roughly increase the supply of water resources by 10 billion cubic meters in the Beijing region in the next 15 years.

The effective management of water resources can effectively reduce the demand for water resources. Water saving and repeated water use should be encouraged by adjusting water price, progressive price increase, seasonal difference price and quality difference price, so as to improve the utilization efficiency of water resources. By consulting the data, it is known that effective management can reduce the water demand by about $30 \%$ in the next 15 years.

The throttling of urban water in Beijing can alleviate the problem of increasing water consumption and insufficient per capita water consumption due to the expansion of the population. Reducing household water consumption will reduce the demand for personal water resources. Consulting the information, we can see that saving water can save $35 \%$ of our individual water demand.

In the aspect of industrial agriculture, we should carry out water-saving technology, strictly control the high water consumption industry, accelerate the transformation of traditional industries, promote water-saving production processes, and improve industrial water recovery and recycling rate. By consulting the data, the successful implementation of water saving measures in all aspects can increase the water supply by about $40 \%$ (Yuan, 1986).

For the intervention plan to improve the pollution, the data show that the daily sewage discharge in Beijing is 2 million 640 thousand M3, and less than half of the concentration of sewage is concentrated. The construction of sewage treatment facilities should be strengthened, the sewage treatment rate and the level of purification should be improved so that the sewage treatment can be reached to the available standard. As a non drinking water 
source, it will be used for industry, agriculture, urban greening and the construction of river and lake environment. If the pollution is improved effectively, the supply can be increased by about $40 \%$.

According to the influence of each policy on water resources supply and demand, we forecasted the supply capacity of water resources after changing. The SMI index after prediction is shown in Figure 10 below:

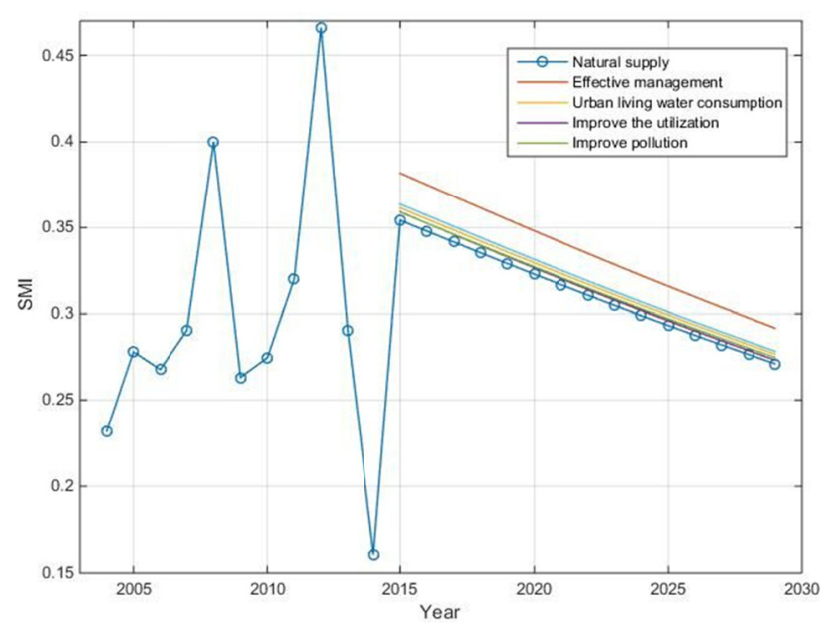

Figure 10. Changes in the predicted SMI indicators after 2015

From the chart, we can see that after the implementation of the intervention plan, the SMI index will rise in different ranges. After the effective management of water consumption, the SMI index will increase the most. The improvement of SMI index is the smallest. Therefore, it can be summed up that, if the successful implementation of the plan, the effective management effect of water consumption for residents is the best, and the effect of sewage improvement is minimal.

It is worth noting that the above intervention plans are implemented in an ideal state. In practice, the implementation effect is often worse due to various factors.

\section{Evaluation and Improvement of Model}

\subsection{The Advantages of the Model}

Despite theFalkenmark Water Stress Indicator gets global acceptance, this indicator has numerous shortcomings. In this model, only the renewable surface and groundwater flows in a country are considered. The model used in this paper not only considers the supply of surface water and groundwater, but also adds the utilization rate of water resources to the model, which makes the model more realistic.

Moreover, the water availability per person is calculated as an average with regard to both the temporal and the spatial scale and thereby neglects water shortages in dry seasons or in certain regions within a country. In this paper, we choose the arid climate of Beijing as the research area. At the same time, we consider the surface water flow and the groundwater discharge in the water supply volume, and make up for the defects of the original model.

Furthermore, it does not take the water quality into account at all nor does it give information about a country's ability to use the resources. Even if a country has sufficient water according to the Falkenmark indicator, these water resources possibly cannot be used because of pollution or insufficient access to them. In this paper, the utilization rate is added to the model, and the demand of water resources is measured directly from three aspects of agriculture, industry and domestic water, so that the model is more perfect.

The SMI index is based on the thought of the existing model, so that the index is both based on and new to the reality.

\subsection{The Disadvantages of the Model}

Many of the assumptions made in the future are based on the assumption of an ideal state. The actual implementation may not be as good as Jiahe's, so it will reduce the effectiveness of the intervention plan. 
The evaluation model does not take into account all the indicators that affect the supply of water resources, and there will be some lack of consideration.

Increase the time coverage, to have a better fit.

\subsection{Improvement of the Model}

Considering more factors that affect water resources, it is more comprehensive to consider the supply and demand of water resources, which can improve the accuracy of the model.

Looking up more information, making the intervention plan more specific, and predicting the data of the prognosis more specifically, can better observe the effect of intervention.

\section{References}

Beijing development and reform committee, Beijing "fifteen" water development plan during the "fifteen" period. The window of Beijing.

Bolognesi, T. (2015). The water vulnerability of metro and megacities: An investigation of structural determinants. Natural Resources Forum, 39(2), 123-133. https://doi.org/10.1111/1477-8947.12056

Brown, A., \& Matlock, M. D. (2011). A review of water scarcity indices and methodologies. White Paper, 106, 19.

Dadson, S., Hall, J. W., Garrick, D., Sadoff, C., Grey, D., \& Whittington, D. (2017). Water security, risk, and economic growth: Insights from a dynamical systems model. Water Resources Research, 53(8), 6425-6438. https://doi.org/10.1002/2017WR020640

Flörke, M., Schneider, C., \& McDonald, R. I. (2018). Water competition between cities and agriculture driven by climate change and urban growth. Nature Sustainability, 1(1), 51-58. https://doi.org/10.1038/s41893-017-0006-8

Gao, Y. Y., Wang, H. R., Han, L, J., Wang, Y., \& Wang, Z. (2010). Beijing water crisis awareness and water resource management mechanism innovation. Resource Science, 32 (2), 274-281.

Han, Z. G. (2014). Mathematical modeling method and its application. Higher Education Press.

Huang, Z. C. (2003). Investigation and analysis of water resources in Beijing city. Journal of Beijing Institute of Civil Engineering and Architecture, (4), 38-41.

Lu, Z. G., Sun, J. D., \& Lu, L. (2002). Beijing drought and Countermeasures. Beijing: Meteorology Press.

Varis, O. (2006). Megacities, Development and Water. International Journal of Water Resources Development, 22(2), 199-225. https://doi.org/10.1080/07900620600648399

Vörösmarty, C. J., McIntyre, P. B., Gessner, M. O., Dudgeon, D., Prusevich, A., Green, P., ... Davies, P. M. (2010). Global threats to human water security and river biodiversity. Nature, 467(7315), 555-561. https://doi.org/10.1038/nature09440

Wu, P. L., \& Lu, Q. (2005). Floating population in Beijing: its increase and influence on the population growth. China Population, Resource and Environment, (3), 27-35.

Yuan, Z. G. (1986). The increasingly serious problem of water shortage, solutions and Countermeasures. Journal of the Chinese Academy of Sciences, (3), 223-226.

Zhang, J. Y., He, R. M., Qi, J., Liu, C. S., Wang, G. Q., \& Jin, J. L. (2013). A further understanding of the water resources in northern China. Water Science Progress, 24(3), 303-310.

Zhang, T. (2004). Analysis of the impact of water shortage on the sustainable development of social and economic development in Beijing city. Beijing Water, (1), 8-9.

Zuo, Q. T. (2011). Calculation of water resources utilization and discussion of threshold. Journal of Hydraulic Engineering, 42(11), 1372-1378.

\section{Copyrights}

Copyright for this article is retained by the author, with first publication rights granted to the journal.

This is an open-access article distributed under the terms and conditions of the Creative Commons Attribution license (http://creativecommons.org/licenses/by/4.0/). 